\title{
Mechanical urethritis and ascendent genitourinary infections due to sexual stimulation of the urethra by inserted foreign bodies
}

\author{
J Péč, Š Straka, F Novomeský, J Kliment, M Péč, Ž Lazárová
}

\begin{abstract}
The cases of 23 men with mechanical urethritis due to insertion of foreign bodies into the urethra are presented. Seven patients had upper urinary tract infections and one died with gangrene of the genitalia and septicaemia.
\end{abstract}

(Genitourin Med 1992;68:399-400)

\section{Introduction}

Mechanical urethritis and ascending genitourinary infections occur in adults most commonly after urological examinations and in children after insertion of foreign bodies into the urethra. ${ }^{1}$

However, in venereologic practice, mechanical urethritis is occasionally encountered in adult men after insertion of foreign bodies into the urethra either by the men themselves or by their sexual partners in order to stimulate an erection of the penis.

We report our experience with 23 cases to highlight the clinical presentation and to point out some serious and even life threatening complications.

\section{Patients and methods}

The patients were 23 men between 16-51 years of age, from all over the territory of Slovakia (population about 5 million) presenting between 1960 and 1990. The patients consulted the doctor either because of their clinical symptoms of urethritis, cystitis, infection of the upper renal tract, septicaemia or because of radiological findings of foreign bodies in the urinary bladder.

All the patients had serological tests for syphilis and cultures from the urethra to exclude Neisseria gonorrhoeae, Trichomonas vaginalis and nonspecific bacterial microflora.

Additional investigations included serum urea and electrolytes, excretion urography and cystoscopy.

\section{Results}

Symptoms of urethritis (a painful burning sensation at urination and urethral discharge) were reported by all 23 patients and in five the discharge was purulent and continuous.

Urethral cultures for Neisseria gonorrhoeae and Trichomonas vaginalis were negative in all cases as were the serological tests for syphilis. A variety of nonspecific bacteria were cultured

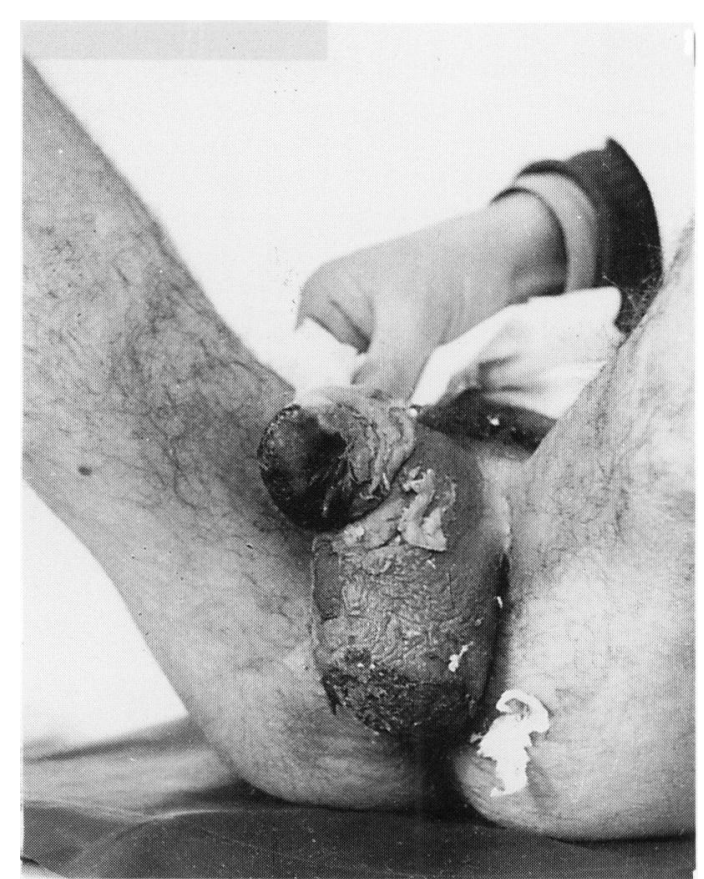

\author{
Address for correspondence: \\ Dr Juraj Péć, Department of \\ Dermatovenereology, \\ Faculty Hospital, Kollárova \\ 2, CS-036 59 Martin \\ Czecho-Slovakia \\ Jessenius Faculty of \\ Medicine, Comeniu \\ University, Martin
}

from the urethra including beta-haemolytic streptococci group B, Streptococcus viridans, and Escherichia coli (table 1).

Seven patients presented with cystitis, cystopyelitis or cystopyelonephritis, and one developed septicaemia and died. He was admitted to the hospital with gangrene of the penis (fig 1) and septicaemia and died 12 hours later. Radiographs revealed a foreign body in his bladder that was identified at necropsy as a metal wire, encrusted with a thick layer of urinary deposits. Subsequent enquiries revealed that he had a single sexual partner who during her visits to his flat requested five

Table 1 Microflora found in 23 patients with mechanical urethritis

\begin{tabular}{lr}
\hline Coagulase-negative staphylococci & 10 \\
Staphylococcus aureus & 2 \\
Beta-haemolytic streptococci group B & 7 \\
Streptococcus viridans & 5 \\
Streptococcus pneumoniae & 1 \\
Escherichia coli & 5 \\
Enterococcus faecalis & 4 \\
Proteus mirabilis & 3 \\
Proteus species & 1 \\
Diphtheroids & 3 \\
Candida albicans & 1 \\
\hline
\end{tabular}

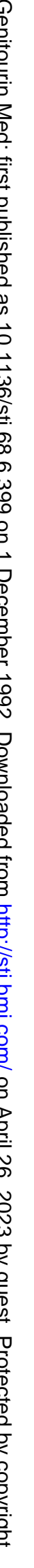

Figure 1 Gangrene of the penis and scrotum caused by the insertion of wire into the urethra. 

encrusted in urinary sediments recovered from the bladder.
Figure 2 A piece of wire
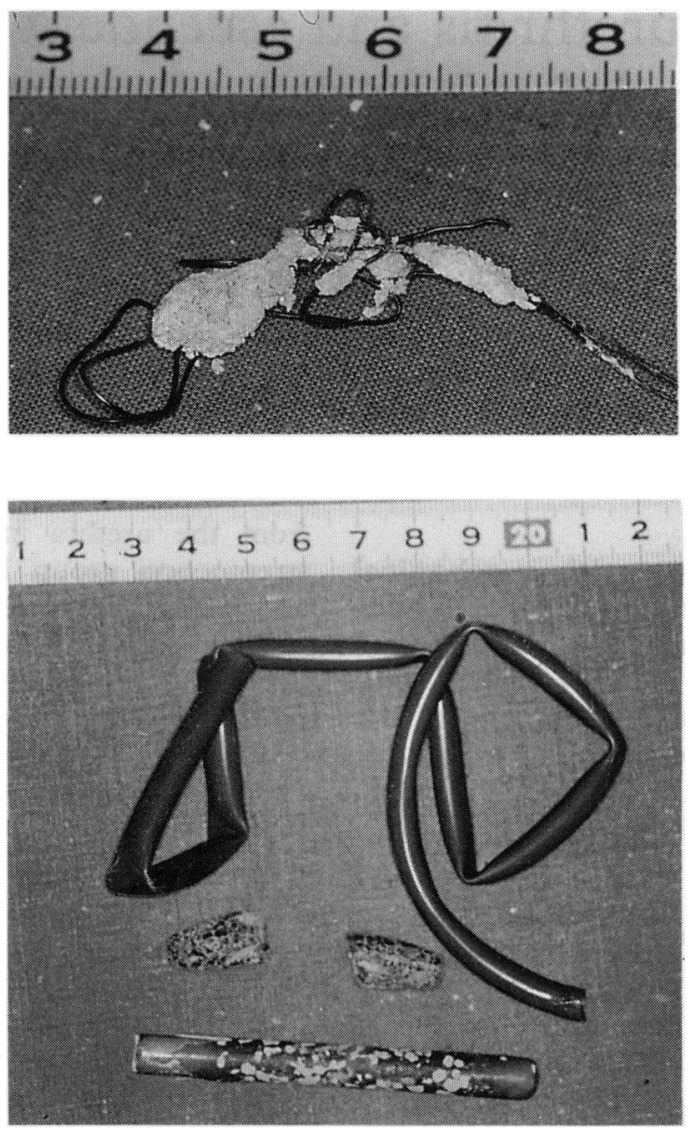

Figure 3 A plastic tube and three fragments of $a$ pencil recovered from the bladder.

Figure 4 Nylon fishing line with a little hook

found fixed in the urinary bladder wall together with a compact urinary stone of $1 \mathrm{~cm}$ size.

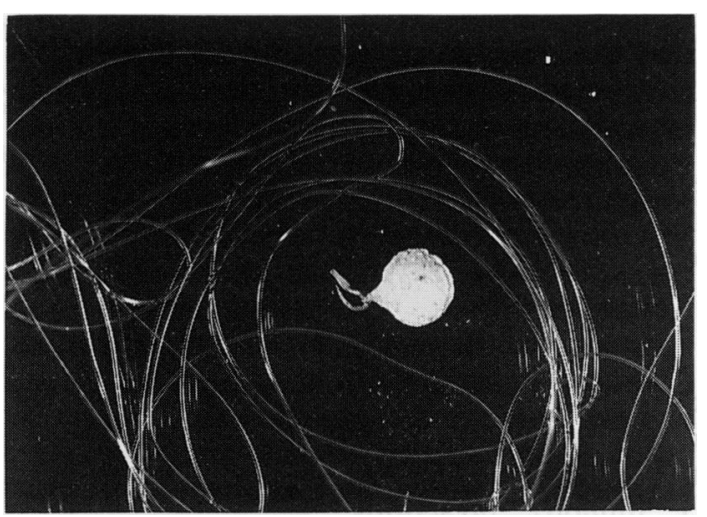

sexual contacts following shortly one after another, and in order to maintain his erection she helped him by inserting pieces of wire into his urethra.

Foreign bodies were surgically removef from the urinary bladders of all the patien and included six patients with pieces of candle, four with hairpins and knitting needles, thrề with pieces of wire (fig 2), four with plastic tubes (fig 3), two with pieces of pencil, and ope each of the following: a thermometer, a nyl fishing line with little hook (fig 4), pieces of straw, and a rubber bottle stopper.

\section{Discussion}

Mechanical urethritis and ascendent urinary tract infection and septicaemia may resut from insertion of foreign bodies into the urethra for the purpose of sexual stimulation

Most foreign bodies removed surgically from the patient's bladders were encrusted in uâjnary deposits suggesting long-term persistenge in the bladder. All these bodies were apparanidy inserted in the urethra as a form of sexux stimulation or to maintain erections. It is likegy that the items were originally inserted into the urethra, during erections and subsequen slipped into the bladder from where they coufd not be manually removed. Some individuafs practiced this kind of sexual stimulation repeatedly as is evidenced by finding of severet pieces of wire and other items in the bladd All the patients were reluctant to confess to such practices and some only confessed the truth in a letter addressed to the doctor prior or after they had sought medical help. Many $\Phi$ the letters suggested underlying sexual or psychological problems in the patient or their sexual partners.

Wooley PD. Recent advances in non-gonococcal urethrid pathogenesis, investigation and treatment. Int $\mathcal{f} S$ AIDS 1990;1:157-60. 